\title{
Crise Ambiental: é Possível Obter Contribuição dos Governos Locais para Minimizá-la? Um Exame do Caso de Pernambuco
}

\section{Environmental Crisis: Is it Possible to Get Local Government Contribution to Minimize it? An Examination of the Case of Pernambuco}

\author{
DOI: $10.46814 / 1 a j d v 3 n 1-019$
}

Recebimento dos originais: 30/10/2020

Aceitação para publicação: 23/12/2020

\section{Ivo Vasconcelos Pedrosa}

Professor e pesquisador aposentado pela Universidade de Pernambuco - UPE; Economista, Doutor em Ciências Econômicas pela UNICAMP - Universidade Estadual de Campinas - São Paulo.

Endereço: rua Casa Forte, 65, apto. 1101, Bairro Casa Forte, Recife, PE.

E-mail: ivovpedrosa@gmail.com

\section{RESUMO}

Como gerar um painel atualizado acerca das alterações nas condições ambientais dos territórios municipais e das ações com vistas à redução dessas alterações? A pesquisa, que teve essa pergunta orientadora, compreendeu os municípios mais populosos de Pernambuco, abrangendo todas as doze "Regiões de Desenvolvimento"1 do Estado, num total de 43, em que habitam 70\% dos pernambucanos. Seu objetivo foi o de examinar a evolução (2002-2010) das alterações nas condições ambientais no território desses municípios, bem como o avanço na utilização de instrumentos de gestão pelos respectivos governos, examinando-se as causas das alterações e da não utilização dos instrumentos de gestão destinados a atenuá-las. Dois índices - o Índice das Pressões Antrópicas (IPA) e o Índice de Atenuação das Pressões Antrópicas pelos Governos Municipais (IAPAM) - permitem uma visão sintética do processo, apontando para os municípios em que são mais críticos, sejam as condições ambientais e o grau e utilização dos instrumentos, seja o conhecimento ou envolvimento dos gestores com a crise ambiental. Além desse núcleo de natureza quantitativa, a pesquisa explorou entrevistas realizadas com os gestores e outros recursos para uma abordagem qualitativa das questões.

Palavras-Chave: Crise ambiental, governos locais, alterações ambientais, Índice das Pressões Antrópicas - IPA, Índice de Atenuação das Pressões Antrópicas pelos Governos Municipais - IAPAM, Pernambuco-Brasil.

\begin{abstract}
How to generate an updated panel on the changes in the environmental conditions of municipal territories and actions to reduce these changes? The survey, which had this guiding question, comprised the most populated municipalities in Pernambuco, covering all twelve "Development Regions" of the State, in a total of 43 , where $70 \%$ of Pernambucans live. Its objective was to examine the evolution (2002-2010) of changes in environmental conditions in the territory of these municipalities, as well as the progress in the use of management instruments by the respective governments, examining the causes of the changes and the non-use of management instruments to mitigate them. Two indices - the Index of Anthropogenic Pressures (IPA) and the Index of Mitigation of Anthropogenic Pressures by Municipal Governments (IAPAM) - allow a synthetic view of the process, pointing to the municipalities where they are most critical, whether environmental conditions and the degree and use
\end{abstract}

\footnotetext{
${ }^{1}$ http://www.bde.pe.gov.br
} 
of instruments, whether the managers' knowledge or involvement with the environmental crisis. In addition to this nucleus of a quantitative nature, the survey explored interviews with managers and other resources for a qualitative approach to the issues.

Keywords: Environmental Crisis, local governments, environmental changes, Anthropogenic Pressures Index - IPA, Mitigation of Anthropogenic Pressures Index by Municipal Governments IAPAM, Pernambuco-Brazil.

\section{INTRODUÇÃO}

Como gerar um painel atualizado acerca das alterações nas condições ambientais dos territórios municipais e das ações com vistas à redução dessas alterações? Especificamente voltado para as ações no âmbito dos governos municipais, o presente trabalho ${ }^{i}$ relata pesquisa que tem como objetivo geral examinar a evolução recente das alterações nas condições ambientais no território dos municípios mais populosos de Pernambuco, o avanço na utilização de instrumentos de gestão pelos respectivos governos, bem como as causas das alterações e da não utilização dos instrumentos de gestão destinados a atenuá-las.

A pesquisa integra amplo painel de esforços relacionados com o planejamento dos territórios, na perspectiva dos gestores públicos municipais, especificamente os voltados para a preservação, a proteção e a recuperação dos recursos naturais, mas com foco na sustentabilidade da sociedade, ou seja, insere-se numa visão que integra meio ambiente e sociedade.

As ações investigadas e que se pretendem melhorar são aquelas voltadas para a caminhada em busca da sustentabilidade das comunidades e de seus cidadãos, atuais e futuros, entendida a sustentabilidade como a melhoria da qualidade de vida, com redução das desigualdades de riqueza e de oportunidade, e preservação da natureza.

Apesar de alcançar os municípios mais populosos de Pernambuco, os resultados da investigação representam contribuição para muitos outros municípios do Estado e do País e se tornam subsídios importantes para a formulação de políticas públicas.

O primeiro ano do período foi objeto da pesquisa do IBGE (ver IBGE, 2005²) e os últimos anos, de pesquisas do grupo coordenado pelo autor. Resultados de anos intermediários - 2006 e 2008 - foram obtidos para alguns subgrupos de municípios e seus resultados foram incorporados a este trabalho.

\footnotetext{
${ }^{2}$ Em 28 de dezembro de 2020 esta publicação não estava mais disponível no portal do IBGE na internet.
} 


\section{REVISÃO DA LITERATURA}

A relação do homem com a natureza passou a ser extremamente relevante na segunda metade do século XX, tendo sido, até então, essencialmente voltada para a dilapidação e a degradação dos recursos naturais (ver múltiplas referências em FOLADORI, 2001). Séculos se passaram em que esses recursos foram tratados como inesgotáveis e a difusão dos resíduos, decorrentes do seu uso, como passível de ser assimilada pela natureza, sem problemas. Considere-se, como evidência dessa demora de ação pela humanidade, o fato de a primeira conferência internacional para proteção ambiental ter sido a realizada em 1900, destinada à preservação de animais, pássaros e peixes da África, e com o objetivo direto de proteger a agricultura (RIBEIRO, 2001, p. 54).

A distância entre os benefícios, obtidos imediatamente com a produção de bens e serviços no presente, e os malefícios, cuja ocorrência é vista como devendo ocorrer num futuro incerto, provoca, em grande parte dos indivíduos e grupos, uma inércia em agir no sentido de contribuir para a correção dos rumos tomados pela humanidade. A consideração dos benefícios está associada ao individualismo, comumente imediatista, enquanto a consciência dos malefícios pressupõe o exercício da solidariedade com as gerações presentes e futuras.

Leuzinger (2003, p. 192-4) resumiu claramente o percurso da criação dos direitos de cidadania, desde o surgimento dos direitos de liberdade ("direitos fundamentais de primeira geração"), passando pelos direitos de igualdade ("direitos fundamentais de segunda geração") até os direitos de solidariedade ("direitos fundamentais de terceira geração"); entre esses últimos, mencione-se o direito ao meio ambiente equilibrado, o que exige de todos a sua proteção. Como decorrência desse direito fundamental, inscrito na Constituição Federal de 1988 no artigo $225^{\mathrm{ii}}$, a autora analisa as funções ambientais - a pública e a privada. Quanto às funções públicas, menciona sua subdivisão em: legislativa, judiciária e administrativa. Ambas as funções - a pública e a privada - decorrem, mais recentemente e de modo mais explícito, do mencionado artigo da Constituição de 1988, que impôs ao poder público e à coletividade o dever de preservar o meio ambiente para as presentes e futuras gerações.

Numa federação, especificamente na brasileira, o espaço público estatal se compõe de subespaços relativos à União, aos Estados e aos Municípios que, no caso das ações relativas aos efeitos da interação homem-natureza, se superpõem, cabendo, cada vez mais, a articulação e a cooperação.

Neves (2006) chamou a atenção para "uma persistente subestimação da contribuição da ação municipal para a melhoria da qualidade ambiental e para o enfrentamento dos processos de degradação do meio ambiente" (p.1). Para ela, uma das evidências dessa subestimação é "o desinteresse em potencializar e difundir as inovações organizacionais e institucionais promovidas pelos Municípios 
brasileiros no campo ambiental, como indica a inexistência de inventários e avaliações sistemáticas sobre o assunto" (p. 1, grifo nosso).

No nível do governo local, no Brasil, a questão se apresenta nos anos noventa, com os esforços iniciais relacionados com a elaboração da Agenda 21. Os resultados alcançados até hoje são, no entanto, reconhecidamente insuficientes, a exemplo dos municípios do Estado de Pernambuco (ver PEDROSA, 2005 e 2006; PEDROSA, REIS \& MUSTAFA, 2006 e 2006a; PEDROSA; SILVA; REIS; LEÃO, 2006; KAKUTA, 2007; PEDROSA; KAKUTA; LEÃO; SILVA, 2007; e PEDROSA; KAKUTA, 2010).

Vários trabalhos têm procurado examinar, especificamente, a relação entre os governos municipais e a crise ambiental. Além do de NEVES (2006), já referido, mencione-se o de Schneider (2000), que sintetizou os componentes de um Sistema Municipal de Proteção Ambiental.

Registre-se que existe na literatura quem constate papel, ainda pequeno, dos governos municipais no enfrentamento da crise ambiental. Mas, também há reconhecimento do significado de experiências exitosas. SANTOS, ULTRAMARI e DUTRA (2002) afirmaram: "À valorização da instância local devem ser creditados muitos dos esforços e experiências bem sucedidas em cidades brasileiras e que servem de exemplo, num processo de constante replicabilidade". Referência importante nesse sentido é o trabalho de Alvim e Kato (2009).

O esforço do Ministério do Meio Ambiente com relação ao papel dos municípios no enfrentamento das questões ambientais pode ser sintetizado no Programa Nacional de Capacitação de Gestores Ambientais (IBAMA, 2006). A sua execução em 2007 representou o início de amplo processo de preparação para os desafios que crescem, apesar dos avanços nas formas de enfrentá-los.

Em Pernambuco, em 2007, o Governo do Estado promoveu a elaboração do Plano Estratégico Ambiental (GOVERNO DO ESTADO DE PERNAMBUCO, 2007). Dentre os programas, destaquese o Qualidade Ambiental e, entre os projetos desse programa, o Sistema Estadual de Informações Ambientais, para o qual certamente este trabalho contribuirá, pois, entre os objetivos do Sistema estão:

a) estruturar banco de dados ambientais, com informações geradas pelos órgãos de governo;

b) assegurar a atualização contínua dos dados e acesso compartilhado a outros bancos de dados;

c) disponibilizar o Relatório de Qualidade Ambiental on line;

d) desenvolver metodologia para indicadores ambientais, valoração econômico-ecológica e quantificação de danos ambientais".

A pesquisa realizada pelo NUPESP ${ }^{\mathrm{iii}}$ com o apoio do CNPq (Edital Universal 01/2002) revelou que os 22 maiores municípios de Pernambuco em população apresentaram, relativamente a 2002, 
Índices de Pressões Antrópicas (sobre o IPA, ver PEDROSA, REIS \& MUSTAFA, 2006) que variam de 0,253 a 0,939 (1,000 representa ausência de danos ambientais provocados por atividades antrópicas). Esses índices foram construídos a partir das respostas dadas pelos gestores ambientais municipais a 99 perguntas acerca de alterações nas condições ambientais provocadas pelas atividades humanas no território do município. Em 2006, entre os 22 municípios com informações disponíveis, os índices variaram de 0,121 a 0,869 (PEDROSA e KAKUTA, 2010).

Com relação ao índice que evidencia o conjunto de políticas públicas municipais em operação (IAPAM - Índice de Atenuação das Pressões Antrópicas pelos Governos Municipais, ver PEDROSA, REIS \& MUSTAFA, 2006), ele se situou, em 2002, entre 0,098, em Abreu e Lima e em Arcoverde, e 0,459 em Recife, para um valor máximo de 1. Em 2006, entre os 22 maiores municípios, os índices variaram de 0,105 em Araripina a 0,744 no Cabo de Santo Agostinho. A exemplo do IPA, esses índices foram construídos com base nas respostas às 133 questões formuladas pelo IBGE na pesquisa de 2002 e reapresentadas em 2006 aos gestores pelo NUPESP.

No que se refere aos dados sobre alterações nas condições ambientais em 2002 (a pesquisa realizada em todos os municípios do país pelo IBGE), utilizados para a construção do IPA, destaquese que foram constatadas as seguintes alterações relevantes que afetaram as condições de vida da população (são indicados entre parênteses os números de municípios que reconheceram as alterações, dentre os 23 investigados): esgoto a céu aberto (19), contaminação do solo (18) e desmatamento (15). Por outro lado, com relação a 2006, dentre 16 municípios, foram as seguintes as três principais alterações constatadas: contaminação do solo (16), poluição do ar (16) e desmatamento (16). Ao indicar as causas das alterações, todos os 16 apontaram, por exemplo, o despejo de esgotos domésticos como causa da poluição das águas e o chorume de lixões como causa da contaminação do solo e, por extensão, da drenagem subterrânea. Outros resultados significativos constatados entre os 16 municípios, em 2006 (pesquisa do NUPESP com a utilização do mesmo questionário do IBGE): 15 encontraram alterações que afetaram a paisagem em razão de ocupação irregular ou desordenada do solo e 14 apontaram degradação de áreas protegidas por desmatamento.

Quanto à utilização de instrumentos de gestão, alguns exemplos podem ser destacados nas pesquisas referentes a 2002 e 2006: embora ainda pequeno, o número de municípios em que funcionou o Conselho Municipal de Meio Ambiente nos últimos 12 meses, anteriores à pesquisa, cresceu: de 8 dentre os 23 em 2002 para 9 de 16 em 2006. Um outro exemplo, desta vez claramente insatisfatório, refere-se ao tratamento dos resíduos sólidos: de 16 municípios com informações referentes a 2006, apenas 7 tinham programa de coleta seletiva e apenas 8 apoiavam a reciclagem de resíduos. 


\section{CARACTERIZAÇÃO DO ESTADO DE PERNAMBUCO}

O Estado de Pernambuco ${ }^{\text {iv }}$ se localiza no centro-leste da região Nordeste do Brasil e possui $98.938 \mathrm{~km}^{2}$. Seu relevo é composto de planície litorânea, planalto central e depressão a oeste. As principais bacias hidrográficas são as dos rios: São Francisco, Capibaribe, Ipojuca, Una, Pajeú e Jaboatão. A vegetação característica é composta por mangue, floresta tropical, na Zona da Mata e caatinga, no Agreste e no Sertão. O clima é tropical atlântico no litoral e semiárido no Agreste e no Sertão.

O Estado, cuja capital é Recife, é dividido em 184 municípios e possui o Distrito Estadual de Fernando de Noronha, que abrange o arquipélago de mesmo nome no Oceano Atlântico.

A população, segundo o Censo de 2000, era de 7.918 mil habitantes, dos quais, 6.058 mil (76,5\%) nas cidades e 1.860 mil $(23,5 \%)$ na zona rural, com uma densidade populacional de 80 habitantes por $\mathrm{km}^{2}$. Os municípios mais populosos eram: Recife (1.422.905 habitantes), Jaboatão dos Guararapes (581.556), Olinda (367.902), Paulista (262.737), Caruaru (253.634) e Petrolina (218.538)

Do ponto de vista das atividades econômicas, Pernambuco participa com 2,7\% do PIB brasileiro e seus principais produtos agrícolas são: mandioca, feijão, cana-de-açúcar e milho. Os maiores rebanhos são de bovinos e caprinos. Na área mineral, os destaques são o calcário e a gipsita e, entre as indústrias, sobressaem as de transformação de minerais não metálicos, confecções, mobiliário e curtume. Mas, o Estado registra a presença de setores tecnologicamente avançados, tais como: assistência médica, informática e turismo.

\section{MÉTODO}

A pesquisa investigou os principais municípios de Pernambuco, definidos a partir do critério da população. Assim, os danos e as medidas preventivas ou reparadoras constatadas são aqueles que atingem uma parte mais significativa dos habitantes do Estado. Buscou-se um conhecimento mais aprofundado sobre o estado do meio ambiente e sobre a atuação do governo municipal mediante:

a) levantamento da evolução, nos anos 2002-2010, das condições ambientais, dos instrumentos de gestão ambiental (fiscalização e outros), utilizados pelos governos municipais, e dos mecanismos de articulação com outras esferas de governo, ONGs etc.;

b) exame específico da experiência com a construção e implementação da Agenda 21 Local;

c) exame da inserção das políticas ambientais em documentos obtidos junto aos gestores. 
O levantamento a que se refere a letra a, acima, foi realizado a partir dos resultados da pesquisa do IBGE sobre meio ambiente (ver IBGE, 2005) e com a aplicação de questionários referentes ao triênio 2008-2010, idêntico ao utilizado pelo IBGE (IBGE, 2005). Os questionários foram enviados em setembro de 2009 e reenviados até mais de uma vez, a partir de, em muitos casos, vários contatos destinados a obter as respostas. O envio foi feito por mensagem eletrônica para endereços obtidos por telefone. As respostas, exceto em apenas dois casos, foram recebidas também por mensagem eletrônica. Em uma das exceções foi usado o aparelho de fax e, em outra, foi entregue pessoalmente ao pesquisador. As respostas foram tabuladas em planilha eletrônica (Excel).

Paralelamente à coleta e análise de dados com base na apuração dos questionários e do exame da evolução 2002-2010, foram feitas entrevistas estruturadas, gravadas, com gestores das Prefeituras abrangidas pela pesquisa, de modo a se investigarem os fatores determinantes, seja das principais alterações ambientais, seja do estágio encontrado na implementação de políticas ambientais municipais.

A entrevista com os gestores buscou:

a) esclarecer possíveis dúvidas surgidas com o preenchimento do questionário;

b) obter documentos que complementem ou ampliem as informações prestadas (leis ou projetos de leis, programas, projetos, orçamentos etc.);

c) indagar sobre as razões para avanços ou recuos observados na comparação entre os índices (IPA e IAPAM ${ }^{\mathrm{vi}}$ ) dos anos de 2002 e 2008-2010, ou 2002, 2006 e 2008-10, a depender do município e de sua participação em levantamentos de anos anteriores.

Em razão da limitação de tempo e recursos, optou-se por buscar alcançar uma fração significativa da população do Estado com menos municípios investigados. Considerou-se importante, também, conhecer a realidade das diversas regiões do Estado. Assim, tomou-se a divisão do Estado em 12 Regiões de Desenvolvimento, uma divisão próxima das microrregiões homogêneas, e se observou a distribuição da população nos principais municípios de cada Região (exceto o Sertão de Itaparica). No total, foram 43 municípios selecionados das várias regiões do Estado em que residem $70 \%$ da população.

\section{RESULTADOS}

Ao todo, nos municípios incluídos na amostra, estavam $70 \%$ da população do Estado. Nos municípios dos quais se obteve respostas ao questionário, em 2008-2010, residem mais da metade dos pernambucanos. 


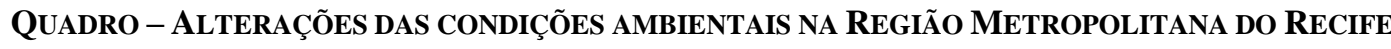

\begin{tabular}{|l|r|}
\hline $\begin{array}{l}\text { O meio ambiente afetou as condições da vida humana? (17 temas e um item } \\
\text { residual) }\end{array}$ & $\begin{array}{l}\text { Respostas } \\
\text { positivas* }\end{array}$ \\
\hline & $\begin{array}{l}2002+2006+2008 \mathrm{a} \\
2010\end{array}$ \\
\hline Alterações ambientais relevantes que afetaram as condições de vida: & 27 \\
\hline 1 - Contaminação de recurso solo & 27 \\
\hline 2 - Ocupação irregular e desordenada do território & 27 \\
\hline 3 - Presença de esgoto a céu aberto & 26 \\
\hline 4 - Desmatamento & 25 \\
\hline 5 - Contaminação de rio, baia, lago, lagoa, açude, represa, etc. & 22 \\
\hline 6 - Poluição do ar & 21 \\
\hline 7 - Poluição sonora & 20 \\
\hline 8 - Deslizamento de encosta & 20 \\
\hline 9 - Presença de vetor de doença (mosquitos, ratos, barbeiros, caramujos etc.) & 18 \\
\hline 10 - Presença de lixão na proximidade de área de ocupação humana & 18 \\
\hline 11 - Queimadas & 18 \\
\hline 12 - Tráfego pesado em vias limítrofes à área urbana & 17 \\
\hline 13 - Inundação & 17 \\
\hline 14 - Doença endêmica ou epidemia (cólera, malária, dengue, febre amarela etc.) & 16 \\
\hline 15 - Redução do estoque pesqueiro & 13 \\
\hline 16 - Contaminação de nascente ou de água subterrânea & 10 \\
\hline 17 - Escassez de água (superficiais ou subterrâneas) & 5 \\
\hline 18 - Outras alterações ambientais relevantes nos últimos 2 anos & \\
\hline
\end{tabular}

* Há algumas grandes diferenças nas respostas entre os 11 municípios da RMR. Esta soma procura mostrar as alterações mais frequentes, nos três momentos investigados. O total máximo de respostas positivas para cada tema seria 33 (11 municípios vezes 3 anos).

A observação do quadro sobre as alterações ambientais, apresentado acima, permite agrupar os danos provocados pela sociedade, segundo os quatro suportes naturais, como segue:

a) solo: está entre os mais citados (com 27 das 33 respostas possíveis), não somente quanto à contaminação como também quanto à presença de esgoto a céu aberto; o solo também se relaciona com o terceiro tema que está no topo da lista: a ocupação irregular e desordenada do território ${ }^{\text {vii; }}$ o quarto item na ordem decrescente de citações - o desmatamento - também diz respeito ao solo, pelos efeitos que provocam nele, de perdas e transformação em áreas desertificadas, bem como de assoreamento dos corpos d’água; nessa mesma linha de perda de solo, com desastres consequentes, está o oitavo item o deslizamento de encosta;

b) água: o quinto item da lista trata da contaminação dos corpos d'água; como visto, relacionada com o terceiro item - presença de esgoto a céu aberto; com o décimo terceiro - inundação -, por sua vez causada por assoreamento e ocupação desordenada das margens dos corpos d'água; os itens décimo sexto e décimo sétimo abordam as questões da contaminação e da escassez da água; neste último caso, o tema menos indicado da Região Metropolitana do Recife; 
c) ar: a sua poluição está mencionada em sexto lugar no ranking, mas os vários fatores determinantes estão em outros itens da lista: esgoto a céu aberto; presença de lixão; queimadas e tráfego pesado em vias limítrofes à área urbana;

d) vegetação: vários são os itens da lista associados com a vegetação: a contaminação do solo; a ocupação irregular (lembre-se a destruição das matas ciliares); o desmatamento; as queimadas; e a inundação.

Além desse painel de alterações, a investigação contou com respostas aos seguintes problemas específicos:

1. alterações dos recursos naturais (ar, água e solo), buscando-se a identificação de possíveis causas:
a) da poluição do ar;
b) da poluição do recurso água;
c) do assoreamento dos recursos d'água;
d) da contaminação do solo;

2. alterações que tenham prejudicado a paisagem ou áreas legalmente protegidas, procurando-se identificar as possíveis causas dessas alterações;

3. prejuízos provocados pelo meio ambiente às atividades econômicas:

a) redução da quantidade ou diversidade ou perda da qualidade do pescado;

b) prejuízos à atividade agrícola;

c) prejuízos à atividade pecuária.

Com referência à ação dos governos municipais, o questionário utilizado (IBGE, 2005) abordou um amplo leque de ações possíveis que podem ser agrupadas da seguinte forma, sem que o elenco seja exaustivo:

a) macroinstrumentos de gestão que dão ao governo municipal condição de, em seu planejamento, estabelecer estratégias e diretrizes para a ação operacional nos vários horizontes de tempo (curto, médio e longo prazos). São eles: a formulação e aprovação, na Câmara Municipal, de legislação ambiental; a criação e operação de Conselho Municipal de Meio Ambiente, paritário, com funções de consulta, normatização, deliberação e fiscalização; a articulação com as demais esferas de governo, mediante 
consórcios, convênios e transferências de atribuições para si; a participação em comitês de bacias hidrográficas; elaboração de plano de gestão e zoneamento ecológico-econômico; e a participação na elaboração e implementação da Agenda 21 Local;

b) instrumentos financeiros de gestão, como a constituição e manutenção de "fundo municipal de meio ambiente", alimentando-o, sobretudo, com taxas de licenciamento ambiental e multas por danos ao meio ambiente; e a busca de recursos externos ao Tesouro Municipal, específicos para o meio ambiente, junto aos Governos Federal e Estadual; neste segundo caso, por exemplo, o ICMS Socioambiental, denominado em vários Estados de ICMS Ecológico;

c) instrumentos de geração de conhecimentos indispensáveis à gestão ambiental, tais como: implantação e operação de estações de monitoramento da qualidade do ar e de recursos hídricos;

d) instrumentos específicos de gestão destinados a mudar comportamentos da sociedade que levem a mais danos aos recursos naturais, bem como desenvolvimento de projetos e atividades voltados à preservação, à prevenção e à recuperação dos recursos ambientais:

em relação ao controle da poluição:

1. programa de coleta seletiva de resíduos sólidos;

2. programa de reciclagem de resíduos sólidos (apoio a cooperativas, instalação de centrais de recolhimento de resíduos da construção etc.);

3. fiscalização e combate a atividades poluidoras (despejos de resíduos, poluição por automóveis etc.);

em relação à gestão dos recursos hídricos:

1. ampliação ou melhoria da rede geral de esgoto sanitário;

2. implantação e melhoria do tratamento de esgoto sanitário;

3. ampliação ou melhoria do sistema geral de abastecimento d'água;

4. dragagem ou limpeza de canais para o escoamento das águas;

5. fiscalização de postos de gasolina;

em relação à gestão de recursos florestais ou de unidade de conservação:

1. contenção de encostas em áreas de risco;

2. controle de queimadas e incêndios florestais;

3. controle de desmatamento;

4. criação ou gestão de unidade de conservação;

5. fiscalização em áreas protegidas e combate às atividades ilegais ali praticadas; 
6. recomposição de vegetação nativa, inclusive de matas ciliares e manguezais;

em relação à gestão de recurso solo:

1. combate ou controle de processos erosivos;

2. controle do uso e limites à ocupação do solo;

3. incentivo à promoção e práticas de agricultura orgânica;

4. introdução de práticas de desenvolvimento rural sustentáveis;

em relação à gestão da atividade pesqueira:

1. fiscalização ou controle de pesca predatória;

em relação a outras ações de caráter ambiental:

1. aplicação de multas;

2. controle de vetores de doenças (mosquitos, ratos etc.);

3. controle, monitoramento ou licenciamento da ocupação urbana;

4. incentivo ao turismo ecológico;

5. programa de educação ambiental.

\subsection{OS ÍNDICES DAS PRESSÕES ANTRÓPICAS - IPA E OS ÍNDICES DE ATENUAÇÃO DAS PRESSÕES ANTRÓPICAS PELOS GOVERNOS MUNICIPAIS - IAPAM}

Os índices constituem um dos resultados significativos da pesquisa, na medida em que permitem uma visão sintética da situação dos municípios, tanto no que se refere às condições do ambiente, quanto à atuação governamental. A sua disponibilidade varia de acordo com as respostas obtidas aos questionários, mas, em alguns casos, é possível dispor de três avaliações, para os anos de 2002 (pesquisa do IBGE), 2006 e 2008-10 (em um dos três anos).

A seguir, reúnem-se as médias e os desvios padrões dos dois índices nos três períodos investigados. Ressaltam-se os seguintes aspectos dos dados:

a) quanto ao IPA:

1. redução ao longo do período, com ritmo maior na primeira metade dos anos considerados;

2. desvio padrão entre um quinto e um terço da média; 
b) quanto ao IAPAM:

1. aumento de quase duas vezes em 2006, em relação a 2002, e recuo de mais de $10 \%$, em relação a 2006, no final do período;

2. desvio padrão de 40 a $60 \%$ da média, indicando maior variabilidade entre os municípios do que no caso do IPA.

\begin{tabular}{|l|r|r|r|r|r|r|}
\hline & \multicolumn{3}{|c|}{ IPA } & \multicolumn{3}{c|}{ IAPAM } \\
\hline & 2002 & 2006 & $2008-10$ & 2002 & 2006 & $2008-10$ \\
\hline Média aritmética simples & 0,776 & 0,516 & 0,505 & 0,166 & 0,300 & 0,264 \\
\hline Desvio padrão & 0,157 & 0,170 & 0,135 & 0,090 & 0,176 & 0,103 \\
\hline Desvio/média & 0,20 & 0,33 & 0,27 & 0,54 & 0,59 & 0,39 \\
\hline
\end{tabular}

A tabela a seguir reúne os índices - IPA - dos municípios, por mesorregião do Estado, buscando-se evidenciar as diferenças entre os índices das diferentes mesorregiões.

Tabela 1 Pernambuco Médias e desvios padrões dos Índices das Pressões Antrópicas - IPA, por mesorregião - 2002,2006 e $2008-10$

\begin{tabular}{|c|c|c|c|c|}
\hline Mesorregião & $\begin{array}{c}\text { Média e desvio } \\
\text { padrão }\end{array}$ & 2002 & 2006 & $2008-10$ \\
\hline \multirow{3}{*}{ RMR } & $\begin{array}{c}\text { Média aritmética } \\
\text { simples }\end{array}$ & 0,662 & 0,521 & 0,503 \\
\cline { 2 - 5 } & Desvio padrão & 0,201 & 0,162 & 0,131 \\
\hline \multirow{2}{*}{ Mata } & $\begin{array}{c}\text { Média aritmética } \\
\text { simples }\end{array}$ & 0,723 & 0,455 & 0,591 \\
\cline { 2 - 5 } & Desvio padrão & 0,148 & 0,286 & 0,049 \\
\hline \multirow{2}{*}{ Agreste } & $\begin{array}{c}\text { Média aritmética } \\
\text { simples }\end{array}$ & 0,838 & 0,478 & 0,500 \\
\cline { 2 - 5 } & Desvio padrão & 0,087 & 0,084 & 0,444 \\
\hline \multirow{2}{*}{ Sertão } & $\begin{array}{c}\text { Média aritmética } \\
\text { simples }\end{array}$ & 0,882 & 0,594 & $*$ \\
\cline { 2 - 5 } & Desvio padrão & 0,081 & 0,270 & \\
\hline
\end{tabular}

* Desvio padrão ausente por se tratar de dado de um só município.

Verificam-se, portanto, as seguintes tendências:

a) com relação a 2002, o IPA varia inversamente com a população, sendo menor e, portanto, refletindo mais alterações antrópicas do ambiente, quanto maior seja a população: de 0,662 na RMR até 0,882 no Sertão; ao mesmo tempo, pode-se observar redução no desvio padrão com o crescimento do índice, indicando mais variabilidade nas regiões mais adensadas populacionalmente; o coeficiente de correlação entre o IPA e a população é - 0,17 ;

b) com relação a 2006, quando os municípios abrangidos são apenas parte do conjunto de 2002, não há tão nítida tendência, embora ainda se observe pequena elevação do índice da Mata em relação ao do Agreste e deste em relação ao do Sertão; 
c) no que se refere a 2008-10, os vinte e três municípios que responderam ao questionário, dos quais apenas um é do Sertão, não apresentam tendência destacável à medida que se passa da RMR para a Mata e para o Agreste.

A seguir, podem ser observadas as médias e desvios padrões do IAPAM dos grupos de municípios das mesorregiões.

Pernambuco Médias e desvios padrões dos Índices de Atenuação das Pressões Antrópicas pelos Governos Municipais IAPAM, por mesorregião - 2002, 2006 e 2008-10

\begin{tabular}{|l|l|r|r|r|}
\hline & & 2002 & 2006 & $2008-10$ \\
\hline RMR & Média aritmética simples & 0,254 & 0,352 & 0,305 \\
\hline & Desvio padrão & 0,108 & 0,182 & 0,114 \\
\hline & & & & \\
\hline MATA & Média aritmética simples & 0,155 & 0,279 & 0,244 \\
\hline & Desvio padrão & 0,046 & 0,074 & 0,091 \\
\hline & & & & \\
\hline AGRESTE & Média aritmética simples & 0,123 & 0,253 & 0,201 \\
\hline & Desvio padrão & 0,066 & 0,179 & 0,068 \\
\hline & & & & \\
\hline SERTÃO & Média aritmética simples & 0,130 & 0,226 & 0,188 \\
\hline & Desvio padrão & 0,052 & 0,204 & 0,053 \\
\hline
\end{tabular}

A exemplo do constatado no IPA, em que o determinante é o processo de ocupação do território, também no IAPAM se verifica uma tendência para menor atuação dos governos locais à medida que se caminha na direção do Sertão, em que pesem não serem grandes as diferenças e, de um modo geral, os índices mostrarem baixa atuação dos governos: a média mais alta, da RMR, alcançou o valor máximo de 0,352 no ano de 2006.

A pesquisa do NUPESP vem se beneficiando dos levantamentos feitos pelo IBGE sobre as várias questões ambientais, inseridos na Pesquisa Informações Básicas Municipais (MUNIC), relativamente a quase todos os anos daquela década ${ }^{\text {viii }}$ O início, como foi visto, ocorreu com o grande suplemento, referente aos anos de 2002 e 2003, publicado em 2005, resultado de um questionário com cerca de 230 perguntas.

Quanto a essa pesquisa, o próprio IBGE sintetiza do seguinte modo a sua parte sobre o meio ambiente:

Nesse contexto, a análise do meio ambiente está assim estruturada: a primeira parte é dedicada à existência dos Conselhos Municipais de Meio Ambiente; a segunda trata de questões relacionadas à existência de estrutura ambiental na prefeitura, quadro de funcionários ligados ao meio ambiente, existência e fontes de recursos financeiros, existência de Fundo Municipal de Meio Ambiente, licenciamento ambiental, articulação na área ambiental com outros 
municípios, temas abordados nesses consórcios, associações ou parcerias, e participação em Comitê de Bacia Hidrográfica; a terceira e última parte analisa as informações relativas às condições ambientais nos territórios dos municípios visando conhecer as ocorrências impactantes observadas, não só as que tenham afetado as condições de vida da população como também aquelas que prejudicaram certas atividades econômicas, especificamente a pesca, a agricultura e a pecuária (IBGE, 2005, p.62).

Utilizou-se, na elaboração deste tópico, o relatório da pesquisa do IBGE (2010) na parte relativa ao meio ambiente.

A pesquisa, da série Perfil dos Municípios Brasileiros, enfocou, para o ano de 2008, a Gestão Pública, compreendendo os seguintes aspectos:

- estrutura e dimensão do quadro de pessoal da administração pública

- legislação e instrumentos de planejamento dos municípios brasileiros

- a gestão municipal na área de habitação

- transporte e

- meio ambiente.

Neste tópico, abordam-se os resultados do último item, relacionado diretamente com a pesquisa do NUPESP.

Os itens pesquisados pelo IBGE são um conjunto pequeno comparado com o questionário aplicado pelo órgão para 2002, cujos resultados compuseram o suplemento especial "Meio Ambiente 2002". O NUPESP, como visto anteriormente, vem aplicando esse questionário, para fins de comparação com o ano-base.

Um panorama baseado nesse levantamento foi traçado abordando-se os seguintes aspectos, dentre os enunciados acima pelo IBGE:
a) o Conselho Municipal de Meio Ambiente;
b) o aparato administrativo voltado para o meio ambiente e o quadro de pessoal nele alocado;
c) os recursos financeiros destinados a essa área;
d) o licenciamento ambiental pelos municípios;
e) o associativismo por meio de consórcios intermunicipais e comitês de bacias hidrográficas;
f) as ocorrências impactantes.

Inicialmente, cabe destacar a dificuldade, inclusive maior do que em pesquisas anteriores, de obter depoimentos dos gestores em entrevistas com o pesquisador. Em um dos municípios foi dito, 
expressamente, que não seria preenchido o questionário porque iria ser "muito ruim para a imagem do município".

Uma indagação ouvida de um profissional com atividades relacionadas com os gestores municipais, a propósito desta pesquisa, chamou a atenção do pesquisador: "é feito algum 'ranqueamento' que indique os municípios melhores e piores"? No relatório da pesquisa não foi incluído ordenamento que não fosse por ordem alfabética, segundo regiões de desenvolvimento, inclusive porque o estabelecimento de ranking de desempenho, boas práticas ou outra qualquer forma de avaliação não constou dos objetivos da pesquisa.

Nas entrevistas, de um modo geral, foi feita, inicialmente, uma apresentação de como os dados com as respostas ao questionário vinham sendo tratadas. Com a cópia da planilha de apuração, foi mostrado que se estava fazendo uma comparação das respostas dadas em 2010 com aquelas dadas ao IBGE em 2002 ou 2003.

Nessa comparação, buscavam-se examinar quatro situações diferentes:

a) a resposta em 2010 foi positiva e igual à de 2002;

b) em 2010, a resposta foi positiva, em oposição à de 2002;

c) em 2010, a resposta foi negativa, em oposição à de 2002; e

d) em ambos os anos a resposta foi negativa.

Quando se trata de alterações nas condições ambientais, a resposta positiva refere-se a dano e afeta negativamente o IPA. Quando se trata de utilização de instrumentos de gestão, a resposta positiva afeta favoravelmente o IAPAM.

\section{CONCLUSÕES}

A pesquisa do NUPESP objeto deste trabalho mostrou aspectos significativos dos impactos antrópicos sobre o ambiente, nos 43 municípios mais populosos do Estado de Pernambuco, bem como as características da gestão ambiental municipal dessas unidades políticas. Nos municípios alcançados pela pesquisa residem $70 \%$ da população do Estado.

O levantamento das alterações antrópicas do ambiente resultou das percepções dos gestores municipais, mediante a utilização de questionário idêntico ao usado pelo IBGE na pesquisa Meio Ambiente - 2002. Por outro lado, em se tratando de um ente de uma federação, os relatos sobre a atuação dos governos locais evidenciaram as relações com as demais esferas de governo - a União e o Estado. 
As alterações ambientais e a atuação dos governos locais foram apresentadas de forma sintética a partir dos índices construídos em pesquisa anterior (Índice das Pressões Antrópicas - IPA e Índice de Atenuação das Pressões Antrópicas pelos Governos Municipais - IAPAM), detalhando-se os resultados por meio de análise das questões postas aos gestores e de suas respostas.

\section{RECOMENDAÇÕES}

É muito frequente, nos contatos com os gestores municipais, que eles demonstrem o interesse em que a pesquisa redunde em ações por parte da Universidade na direção de melhoria da gestão municipal.

Por esse motivo, procura-se, neste tópico, indicar caminhos para os gestores quanto a esforços a serem empreendidos no planejamento das ações dos governos municipais. Apresentam-se programas, projetos, atividades ou ações, encontradas com mais frequência entre os municípios pesquisados e que podem servir de roteiro para a melhoria da atuação de governos que ainda não alcançaram o estágio de utilizar determinados instrumentos de gestão.

Mencionam-se, a partir dos resultados obtidos, elementos de uma gestão ambiental cuja presença deveria ser buscada por todos os governos municipais:

a) o encaminhamento, à Câmara de Vereadores, de projetos de legislação específica para a questão ambiental;

b) o funcionamento regular de um Conselho Municipal de Meio Ambiente, de composição paritária entre governo e sociedade civil, com funções normativa, deliberativa e consultiva, sob a presidência do gestor ambiental do governo municipal; o Conselho deve estar atento às diretrizes, restrições, limites e incentivos estabelecidos no Plano Diretor do Município, aprovado por Lei Municipalix

c) um órgão ambiental, na forma de secretaria ou ligado a uma Secretaria, mas com atribuições em todas as áreas da gestão ambiental e ativo em termos de articulação com todos os outros órgãos e entidades do governo local, tendo em vista o caráter transversal das questões ambientais; setor indispensável desse órgão é a estrutura de fiscalização (despejo inadequado de resíduos domésticos e industriais, atividades poluidoras e outras);

d) um programa de educação ambiental;

e) um fundo específico para receber recursos relacionados com as ações ambientais (licenciamento ambiental, multas por infração à legislação ambiental, recursos do ICMS Socioambiental etc.) e destinado a apoiar projetos de proteção ou recuperação do meio ambiente;

f) participação em consórcios, como os destinados à disposição de resíduos sólidos, tratamento de esgoto urbano e outros, visando a ampliar a capacidade de realização e reduzir custos operacionais;

g) implantação de sistema de coleta seletiva de resíduos sólidos, compreendendo: estímulo à estruturação de cooperativa de recicladores, implantação de programa de conscientização da população quanto à importância de recuperar materiais aproveitáveis bem como de reduzir o custo com o tratamento e a disposição de resíduos;

h) identificação de projetos ou atividades de interesse ambiental e busca de parcerias com órgãos públicos, ONGs, empresas estatais e privadas, instituições internacionais e universidades;

i) identificação de atribuições da $\mathrm{CPRH}^{\mathrm{x}}$ que possam ser transferidas para o município;

j) participação em comitê de bacia hidrográfica na qual se situa o município, integral ou parcialmente; iniciativa visando à sua criação, se ele ainda não existe; 
k) retomar ou iniciar o processo de elaboração, implementação e acompanhamento da Agenda 21 do Município, iniciando com a criação de um Fórum com a participação dos segmentos mais representativos da sociedade que conduza o processo até o acompanhamento da execução do Plano de Desenvolvimento Sustentável do município;

É claro que se torna necessário, em face da escassez de recursos humanos, estabelecer-se uma escala de prioridades, o que pode ser obtido no âmbito do Conselho Municipal do Meio Ambiente e do Fórum da Agenda 21, quando instalados ou reinstalados. 


\section{REFERÊNCIAS}

ALVIM, Angélica A. T. B.; KATO, Volia R. C. Planos diretores e legislações ambientais em áreas de proteção de mananciais: conflitos e possibilidades de integração. In: Anais do XIII Encontro da Associação Nacional de Pós-graduação e Pesquisa em Planejamento Urbano e Regional. Disponível em http://www.anpur.org.br/anais/ena13/ARTIGOS/GT4-32-954-20090320083431.pdf. Acesso em 25 de dezembro de 2010.

BRASIL. CONFEA; MINISTÉRIO DAS CIDADES. Plano Diretor Participativo; guia para a elaboração pelos municípios e cidadãos. CONFEA e Ministério das Cidades, 2004. Disponível em http://www.cidades.gov.br/secretarias-nacionais/programas-urbanos/biblioteca/plano-

diretor/materiais-de-capacitacao/planejamento-territorial-e-plano-diretor-participativo/. Acesso em 22 de novembro de 2010.

DRUMMOND, Conceitos básicos para a análise de situações de conflito em torno de recursos naturais. In: BURSZTYN, Marcel (org.). A difícil sustentabilidade; política energética e conflitos ambientais. Rio de Janeiro: Garamond, 2001.

FOLADORI, Guillermo. Limites do desenvolvimento sustentável. Campinas, UNICAMP, 2001.

GOVERNO DO ESTADO DE PERNAMBUCO. Plano Estratégico Ambiental. Recife, 2007 http://www.ibge.gov.br/home/estatistica/populacao/atlas_saneamento/pdfs/mappag99.pdf. Acesso em 07 de outubro de 2010.

- Pernambuco; dados. Disponível em http://www.portaisgoverno.pe.gov.br/web/portalpe/dados. Acesso em 25 de novembro de 2010.

IBGE. Perfil dos Municípios Brasileiros - Gestão Pública 2008. Disponível em http://www.ibge.gov.br/munic2008/index.php. Acesso em 01 de novembro de 2010.

Perfil dos Municípios Brasileiros - Meio Ambiente 2002. Disponível em http://www.ibge.gov.br/home/estatistica/economia/perfilmunic/meio_ambiente_2002/meio_ambiente 2002.pdf. Acesso em 05 de novembro de 2010. (Obs.: em 28 de dezembro de 2020 este site não foi encontrado no portal do IBGE).

. Indicadores de Desenvolvimento Sustentável - Brasil 2008. Rio de Janeiro: IBGE, 2008.

LANGONE, Cláudio. SISNAMA - Gestão Compartilhada e Descentralizada; O Papel do Município na Gestão Ambiental. Apresentação no Congresso da Sociedade Nordestina de Ecologia - Gravatá/PE. Outubro de 2009.

LEUZINGER, Márcia. Competências federativas e fiscalização ambiental: uma complementaridade necessária, mas inacabada. NASCIMENTO \& DRUMMOND (orgs.). Amazônia; dinamismo econômico e conservação ambiental. Rio de Janeiro: Garamond, 2003.

MELO, Jorge André C. de. Cooperação federativa entre Estado e Município: o caso do Programa de Apoio ao Desenvolvimento Sustentável da Zona da Mata de Pernambuco (PROMATA) no Município de Glória do Goitá - PE. Recife, 2009. 135 f. Dissertação (Mestrado em Gestão do Desenvolvimento Local Sustentável - GDLS) - Faculdade de Ciências da Administração de Pernambuco da Universidade 
de Pernambuco, Recife, UPE, 2009. Disponível em <http://www.capes.gov.br>. Acesso em 20 de outubro de 2010.

NEVES, Estela M. S. C. Federalismo e governança ambiental: a perspectiva dos municípios brasileiros. FUNDAJ, I Seminário Brasileiro de Governança Ambiental: Contexto, Realidade, Rumos. 28 a 30 de novembro de 2006. Recife. 28p.

NUPESP (Núcleo de Pesquisas em Economia do Setor Público). Os Municípios e o Meio Ambiente em Pernambuco; relatório de pesquisa - 2006-2007. Recife, 2007. Disponível em http://www.nupesp.org/arquivos/2006_2007_Relatorio_Meio_Ambiente.doc. Acesso em 14 de setembro de 2010.

PAULO, Felipe Luiz Lima de. O Imposto sobre Circulação de Mercadorias e Serviços - ICMS Socioambiental como incentivo à melhoria das políticas públicas ambientais em nível municipal: o caso de Municípios da Região Metropolitana do Recife - PE. 152 f. Dissertação (Mestrado em Gestão do Desenvolvimento Local Sustentável - GDLS) - Faculdade de Ciências da Administração de Pernambuco da Universidade de Pernambuco, Recife, UPE, 2009. Orientador: Ivo Vasconcelos Pedrosa. Disponível em <http://www.capes.gov.br>. Acesso em 20 de outubro de 2010.

PEDROSA, Ivo V. Monitoramento de alterações das condições ambientais e das ações dos governos municipais: experiência dos municípios pernambucanos. Trabalho apresentado no I Seminário Nacional sobre a Governança Ambiental no Brasil - Contexto, Realidades, Rumos, promovido pela Fundação Joaquim Nabuco - FUNDAJ, Recife, em 30 de novembro de 2006. Disponível em http://upe.academia.edu/IvoPedrosa/Papers/152511/MONITORAMENTO_DE_ALTERACOES_DA S_CONDICOES_AMBIENTAIS_E_DAS_ACOES_DOS_GOVERNOS_MUNICIPAIS_EXPERIE NCIA_COM_MUNICIPIOS_PERNAMBUCANOS. Acesso em 06 de novembro de 2010.

PEDROSA, Ivo V.; KAKUTA, Adriana Érika. Condições do meio ambiente e gestão ambiental em municípios pernambucanos. Trabalho apresentado na Conferência da Terra, em Olinda, maio de 2010. Disponível em www.conferenciadaterra.com. Acesso em 6 de novembro de 2010.

PEDROSA, Ivo V.; KAKUTA, Adriana E.; LEÃO, Clarissa Z. C.; SILVA, Erasto M. da. Os Municípios e o Meio Ambiente em Pernambuco - Relatório de pesquisa - 2006-2007. Recife, setembro de 2007. 178p.

PEDROSA, Ivo V.; REIS, André C.; SILVA, Erasto M. da. (2009). Condições ambientais e ações dos governos dos municípios mais populosos de Pernambuco. Gestão e Sociedade, v. 2 n. 3 (2008): janeiro/junho; https://doi.org/10.21171/ges.v2i3.550. Publicado em 17-07-2009 (https://www.gestaoesociedade.org/gestaoesociedade/article/view/550).

PEDROSA, Ivo V.; REIS, André Casimiro; SILVA, Erasto Mustafa da. Políticas públicas municipais relacionadas com a melhoria do ambiente urbano no Estado de Pernambuco: limitações $e$ possibilidades. In: III Encontro da ANPPAS, 2006, Brasília. Anais do III Encontro da ANPPAS. Brasília: ANPPAS, 2006.

PEDROSA, Ivo V.; SILVA, Erasto Mustafa da; REIS, André Casimiro; LEÃO, Clarissa Z. C. Monitoramento de Políticas Ambientais Municipais: uma experiência em Pernambuco. In: $11^{\circ}$ Congresso Nordestino de Ecologia, 2006, Recife. Meio Ambiente no Nordeste: avanços e desafios. Recife: Sociedade Nordestina de Ecologia, 2006. 
RIBEIRO, Wagner C. A ordem ambiental internacional. São Paulo: Contexto, 2001.

SANTOS, ULTRAMARI e DUTRA. Artigo-base sobre o meio ambiente urbano. In: CAMARGO, Aspásia; CAPOBIANO, João Paulo R.; José Antônio P. de. (orgs.) Meio ambiente Brasil: avanços e obstáculos pós-Rio-92. São Paulo: FGV, Instituto Sócio-Ambiental e Estação Liberdade, 2002, p. $337-$ 356.

SCHNEIDER, E. (2000). Gestão ambiental municipal: preservação ambiental e desenvolvimento sustentável. Anais do Encontro Nacional de Engenharia da Produção, São Paulo, SP, Brasil.

TOPAN, Cláudia S. de O. Unidades de Conservação, Federais e Estaduais, no Estado de Pernambuco: situação legal, infraestrutura e plano de manejo. Monografia (Curso de Especialização em Desenvolvimento Sustentável e Meio Ambiente). Instituto de Ciências Biológicas da Universidade de Pernambuco - UPE. Orientador: Clemente Coelho Júnior. Recife, 2009.

VILARIM, Pedro. Indicadores da gestão ambiental municipal em Pernambuco. Disponível em http://pedrovilarim.blogspot.com/2009/01/indicadores-da-gestao-ambiental.html. Acesso em 22 de novembro de 2010.

\footnotetext{
${ }^{\mathrm{i}}$ Os seguintes membros do NUPESP (Núcleo de Pesquisas em Economia do Setor Público - https://www.nupesp.org e https://www.facebook.com/nupesp) contribuíram para os resultados da pesquisa: a) dos pesquisadores, Cristiano Corrêa e Felipe Luiz Lima de Paulo; b) dos estudantes de iniciação científica, Ana Clara de Queiroz Lins Martins, Gabriela de Carvalho Lefosse Valgueiro, Gabriela Iara Costa Sena, Luciana Leocádio de Almeida, e Manuela Feitosa de Lima Nascimento. A pesquisa contou com o apoio do CNPq a partir de aporte de recursos do Edital MCT/CNPq n ${ }^{\circ}$ 014/2008 - Universal, concedidos ao líder do NUPESP, autor deste artigo, bem como de concessão de bolsas de iniciação científica por meio de editais da Universidade de Pernambuco - UPE, tanto as concedidas pelo CNPq, por intermédio da Universidade, quanto as concedidas pela Fundação de Amparo à Ciência e Tecnologia de Pernambuco (FACEPE) e pela Faculdade de Ciências da Administração de Pernambuco, da UPE. Os dados de 2006, incorporados a este relatório, para compor o período 2002-2010, também foram obtidos com o apoio do CNPq e das outras instituições mencionadas. No caso do CNPq, por meio de auxílio do Edital Universal 01/2002. A partir de 2011 o NUPESP deu continuidade às investigações com recursos do Edital Universal no 14/2010 do CNPq.

ii “Art. 225. Todos têm direito ao meio ambiente ecologicamente equilibrado, bem de uso comum do povo e essencial à sadia qualidade de vida, impondo-se ao Poder Público e à coletividade o dever de defendê-lo e preservá-lo para as presentes e futuras gerações."

iii Núcleo de Pesquisas em Economia do Setor Público, um grupo presente no Diretório de Grupos de Pesquisa do CNPq: http://dgp.cnpq.br/dgp/espelhogrupo/27038.

${ }^{\text {iv }}$ Este tópico se baseia no Portal oficial do Governo do Estado de Pernambuco na internet (GOVERNO DO ESTADO DE PERNAMBUCO, 2010).

v Segundo os resultados preliminares do Censo 2010 (IBGE, 2010), a população atual destes municípios é: Recife (1.472.202), Jaboatão dos Guararapes (623.471), Olinda (357.965), Paulista (278.651), Caruaru (306.788) e Petrolina (287.233). Esses números revelam uma desconcentração, na qual se destacam o decréscimo da população de Olinda (3\%) e o crescimento das de Petrolina $(31 \%)$ e Caruaru $(21 \%)$.

${ }^{\mathrm{vi}}$ Acerca dos índices (IPA e IAPAM), ver PEDROSA, REIS \& MUSTAFA, 2006.

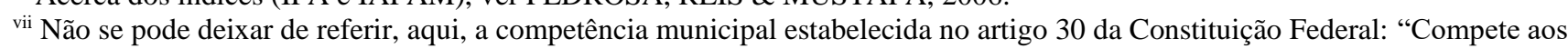
Municípios: ... VIII - promover, no que couber, adequado ordenamento territorial, mediante planejamento e controle do uso, do parcelamento e da ocupação do solo urbano;"

viii Ver a interessante síntese da pesquisa para o Estado de Pernambuco, georreferenciada, em VILARIM (2010).

ix "Fazer planejamento territorial é definir o melhor modo de ocupar o sítio de um município ou região, prever os pontos onde se localizarão atividades, e todos os usos do espaço, presentes e futuros. Pelo planejamento territorial, pode-se converter a cidade em benefício para todos; podem-se democratizar as oportunidades para todos os moradores; podem-se garantir condições satisfatórias para financiar o desenvolvimento municipal; e podem-se democratizar as condições para usar os recursos disponíveis, de forma democrática e sustentável” BRASIL. CONFEA; MINISTÉRIO DAS CIDADES, 2010 (2004).

${ }^{x}$ Agência Estadual de Meio Ambiente e Recursos Hídricos.
} 